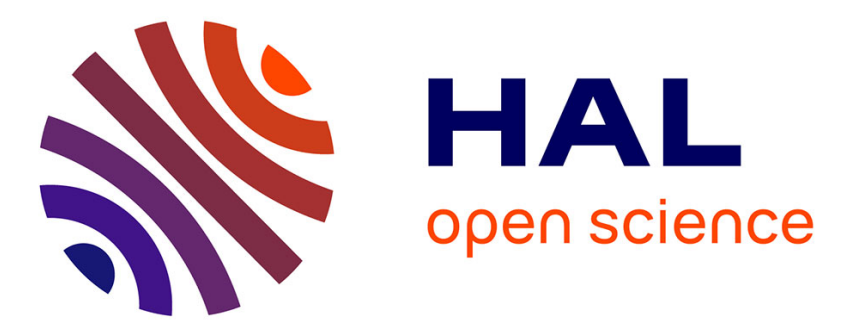

\title{
Cavity enhanced FTIR spectroscopy using a femto OPO absorption source
}

\author{
Xavier de Ghellinck d'Elseghem Vaernewijck, Keevin Didriche, Clement \\ Lauzin, Atina Rizopoulos, Michel Herman, Samir Kassi
}

\section{To cite this version:}

Xavier de Ghellinck d'Elseghem Vaernewijck, Keevin Didriche, Clement Lauzin, Atina Rizopoulos, Michel Herman, et al.. Cavity enhanced FTIR spectroscopy using a femto OPO absorption source. Molecular Physics, 2011, 109, pp.2173-2179. 10.1080/00268976.2011.602990 . hal-00722799

\section{HAL Id: hal-00722799 \\ https://hal.science/hal-00722799}

Submitted on 4 Aug 2012

HAL is a multi-disciplinary open access archive for the deposit and dissemination of scientific research documents, whether they are published or not. The documents may come from teaching and research institutions in France or abroad, or from public or private research centers.
L'archive ouverte pluridisciplinaire HAL, est destinée au dépôt et à la diffusion de documents scientifiques de niveau recherche, publiés ou non, émanant des établissements d'enseignement et de recherche français ou étrangers, des laboratoires publics ou privés. 


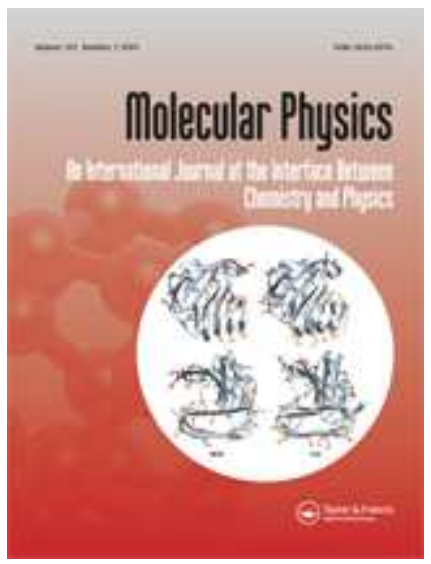

\section{Cavity enhanced FTIR spectroscopy using a femto OPO absorption source}

\begin{tabular}{|r|l|}
\hline Journal: & Molecular Physics \\
\hline Manuscript ID: & TMPH-2011-0137.R1 \\
\hline Manuscript Type: & Special Issue Paper - Dijon HRMS \\
\hline Author: & 24-Jun-2011 \\
\hline Complete List of Authors: & $\begin{array}{l}\text { de Ghellinck D'Elseghem Vaernewijck, Xavier; Université Libre de } \\
\text { Bruxelles, Chimie quantique et Photophysique } \\
\text { Didriche, Keevin; Université Libre de Bruxelles, Chimie quantique et } \\
\text { Photophysique } \\
\text { LAUZIN, Clement; Université Libre de Bruxelles, Chimie quantique } \\
\text { et Photophysique } \\
\text { Rizopoulos, Atina; Université Libre de Bruxelles, Chimie quantique } \\
\text { et Photophysique } \\
\text { Herman, Michel; Université Libre de Bruxelles, Chimie quantique et } \\
\text { Photophysique } \\
\text { Kassi, Samir; Universite Joseph Fourier, Laboratoire } \\
\text { Interdisciplinaire de Physique }\end{array}$ \\
\hline Keywords: & $\begin{array}{l}\text { Cavity enhanced absorption spectroscopy, FTIR, Femtosecond OPO } \\
\text { comb spectroscopy, Femto-FT-CEAS }\end{array}$ \\
\hline \hline
\end{tabular}

\section{SCHOLARONE \\ Manuscripts}


REVISED

Molecular Physics

Special issue for Di Lonardo

\title{
Cavity enhanced FTIR spectroscopy using a femto OPO absorption source.
}

\section{X. de Ghellinck d'Elseghem Vaernewijck*, K. Didriche**, C. Lauzin, A. Rizopoulos and M. Herman}

\author{
Chimie quantique et Photophysique CP160/09 \\ Faculté des Sciences \\ Université Libre de Bruxelles (U.L.B.) \\ Av. Roosevelt, 50 \\ B-1050, Bruxelles \\ Belgium
}

\author{
S. Kassi \\ Laboratoire Interdisciplinaire de Physique (UMR 5588 CNRS-UJF) \\ Université Joseph Fourier \\ BP 87 F-38402 Saint-Martin d'Hères \\ France
}

* FRIA researcher

** Postdoctoral Researcher (F.R.S.-FNRS)

Pages: 21

Figures: 8

Tables: 1

Send mail to Prof. M. Herman, mherman@ulb.ac.be 


\begin{abstract}
The $v_{1}+v_{3}$ band of ${ }^{12} \mathrm{C}_{2} \mathrm{H}_{2}$ was recorded using a high resolution continuous scan Fourier transform interferometer fitted with a femto OPO absorption source. Various experimental schemes were successfully implemented, including multipass absorption in a cell and also in a supersonic expansion, and cavity enhanced absorption. An optimal rms noise equivalent absorption of $2.210^{-9}$ $\mathrm{cm}^{-1} \mathrm{~Hz}^{-1 / 2}$ per spectral element was reached in the latter case, corresponding to $\alpha_{\min }=1.510^{-7} \mathrm{~cm}^{-1}$. Performances are illustrated and discussed.
\end{abstract}

\title{
Keywords
}

Keywords: Cavity enhanced absorption spectroscopy; FTIR, Femtosecond OPO comb spectroscopy, Femto-FT-CEAS 


\section{Introduction}

Michelson-type Fourier transform interferometers (FTIR) are widely used in high resolution molecular infrared spectroscopy since pioneering studies such as those by, in alphabetical order, Brault $(1,2)$, Delbouille $(3,4)$, Guelachvili (5,6), Johns (7,8), Kauppinen $(9,10)$, Valentin (11,12), Winnewisser $(13,14)$ and their co-workers. More recently, new types of absorption schemes were developed to increase the signal and boost the detection sensitivity with FTIR instruments. For instance brighter absorption sources were used, such as synchrotron radiation (15) and broadband femto lasers $(16,17)$, with conventional single or multipass absorption cells. Others were based on conventional sources with high finesse cavities to perform cavity enhanced absorption spectroscopy (CEAS) (18). Attempts to combine laser sources with CEAS and FTIR detection were also reported. Successful experiments include FT-CRDS $(19,20)$ and FT-ICLAS (for intracavity laser absorption spectroscopy) (21,22) schemes. In 2010 cavity enhanced FTIR spectroscopy using a femtosecond laser absorption source was also reported $(23,24)$, which we labeled Femto-FT-CEAS. The cavity modes comb was locked onto the Ti:Sa femto laser comb (the so-called "magic point (MP) $(25,26))$, detecting e.g. at ULB $\mathrm{O}_{2}$ present in the atmosphere between the mirrors of the high finesse cavity open to air (23). We wish to report here on attempts to repeat such experiments, now using a tunable femto OPO absorption source and acetylene, $v_{1}+v_{3}$ (the symmetric and antisymmetric $\mathrm{CH}$ 
stretching vibrations, respectively) as molecular band. In section 2 , the successful use of a bright femto OPO absorption source for FTIR is presented, using various multipass arrangements. A more refined high-finesse cavity design is described in section 3 to achieve OPO-Femto-FT-CEAS. Performances are further illustrated in the final section, which also concludes the present "proofs of principles"-type report. Although the present experiments will not involve locking the cavity comb onto the femto comb and are sometimes referred to as of integrated cavity output spectroscopy (ICOS) type, the latter is often associated to cavity off-axis experiments which is not the case here. We shall therefore keep using the more general CEAS terminology.

\section{Use of a femto OPO absorption source}

In our previous work,(23) a femto Ti:Sa source (Coherent Chameleon ULTRA II) served as absorption source. This laser is a mode locked laser with $80 \mathrm{MHz}$ repetition rate and $140 \mathrm{fs}$ laser pulse width. We have now used this laser to pump an OPO module (Coherent PP810), allowing for broader wavelength coverage towards the IR. In principle, the full range $1-3 \mu \mathrm{m}$ is available if one also accounts for the idler option. It is, however limited by atmospheric water absorption which prevents laser operation in the lower IR 
water bands. This problem also occurs in the NIR in specific ranges between 7000 and $7500 \mathrm{~cm}^{-1}$, as demonstrated in Figure 1. This figure also illustrates the typical bandwidth available for each experiment, which is about $90 \mathrm{~cm}^{-1}$ FWHM in the range probed during the present experiments on acetylene $(1.47-1.53 \mu \mathrm{m})$. Each recording comes with a base line extending over the full spectral range appearing in Figure 1. Thus the observed base line in the Figure merges the noise of all individual recordings. We shall here mainly focus on the lower energy region in Figure 1.

We first checked that the use of the OPO module was compatible with the high resolution Bruker IFS120HR FTIR continuous acquisition procedure. The success of these experiments is illustrated in Figure 2 presenting a spectrum of acetylene in a supersonic expansion, recorded at 3 $10^{-2} \mathrm{~cm}^{-1}$ resolution (defined as 0.9 /maximum optical path difference). A multipass optics made of two drilled gold mirrors was used, set to 25 passes in the expansion produced using a circular nozzle ( $0.5 \mathrm{~mm}$ inner diameter), the central hole in the mirrors allowing for light input and exit as previously described in the literature (27). We have used the latest version of the FANTASIO+ set-up (for "Fourier transform, tunable diode laser and mass spectrometers interfaced to a supersonic expansion") built at ULB to produce jet-cooled acetylene. This set-up is described in the literature and not further detailed $(28,29)$. Precise experimental conditions are provided in the caption 
of Figure 2. We checked that the gain in $\mathrm{S} / \mathrm{N}$ is about one order of magnitude compared to the use of a globar absorption source, other experimental conditions being identical.

In a second step we achieved multipass absorption in a room temperature cavity. The cavity, $90 \mathrm{~cm}$ long, was identical to the one further described in the next section. The off-axis CEAS design was set to reach about $5 \mathrm{~m}$ absorption pathlength. The $\mathrm{C}_{2} \mathrm{H}_{2}, v_{1}+v_{3}$ band was again recorded, now under room temperature conditions. A spectral portion is presented in Figure 3 (top). Sharp negative signals corresponding to saturated peaks were removed (as in forthcoming Figures) by using a subroutine suppressing the corresponding data points from the spectra, thus after Fourier transforming the recorded interferogram. The theoretical spectrum also shown in this figure (bottom) is calculated using the parameters from the global model by Amyay et al. (30). The regular series of lines missing in the simulation from 6535 to $6510 \mathrm{~cm}^{-1}$ is due to ${ }^{13} \mathrm{CH}^{12} \mathrm{CH}$ present in natural abundance in the sample (2\%). The observation of this isotopologue is a nice illustration of the quality of the experimental data. The noise level reveals a minimal absorbance of $510^{-3}$, i.e. an absorption detection limit $\bullet_{\min }=10^{-5} \mathrm{~cm}^{-1}$.

In a third step, we attempted to perform on-axis CEAS in a room temperature high finesse cavity. A major limitation was, however encountered, compared to our previous Ti:Sa experiments (23). It indeed 
turned out that the manufactured tuning mechanism involves a dispersion element that inherently adds chirp. This prevented us from efficiently locking together the cavity and OPO combs, thus from reaching the MP. This problem was not encountered in previous experiments using only the Ti:Sa pump source (23) since there is no similar dispersion element as in the OPO. As a result all experiments were performed outside from the MP, by scanning the cavity length using a piezoelectric actuator (PZT) (HPST 1000 modulator) as described in the next section.

\section{CEAS experiments}

The set-up for CEAS experiments is schematized in Figure 4. Broadband injection of a high-finesse cavity was achieved using a pair of lenses $\left(\mathrm{L}_{1}\right.$ and $\left.\mathrm{L}_{2}, \mathrm{f}=50 \mathrm{~mm}\right)$. The cavity was made of half inch output couplers (Layertec) stated to have $99.3 \%$ reflectivity $\left(\mathrm{CM}_{1}\right.$ and $\left.\mathrm{CM}_{2}\right)$. It corresponds to a finesse $\mathcal{F}=\frac{\pi \sqrt[4]{R_{1} R_{2}}}{1-\sqrt{R_{1} R_{2}}} \geq 445$ ). The output cavity mirror was set on a PZT. The cavity was about $77 \mathrm{~cm}$ long and the PZT was permanently modulating the cavity length. In this way, cavity modes are jittering and on the average every laser mode is equally transmitted, leading to a smooth transmission spectrum. Conditions need to be adapted empirically by tuning the cell length to a slightly different value for each selected central 
wavelength and for each sample conditions (pressure) to optimize this fringing smoothing effect.

The laser beam was sent through a HoYag type optical Faraday isolator (Thorlabs) before injection in the cavity, to avoid optical feedback in the laser oscillator. This prooved to be essential in the success of the experiments.

The output laser beam was directed into the high resolution continuous scanning FTIR equipped with an InGaAs diode detector. The entrance FTIR iris aperture was set to $1.15 \mathrm{~mm}$, i.e. larger than the laser beam diameter, the latter being focused to $10 \mu \mathrm{m}$ at the FTIR entrance, using a $12.5 \mathrm{~cm}$ focal lens $\left(\mathrm{L}_{3}\right)$. Spectra are presented in Figures 5 and 6, illustrating various features.

As shown in Figure 5, the modulation frequency of the PZT had to be set as high as possible $(20 \mathrm{kHz})$ to reduce the noise level. This figure presents the same spectral range recorded using various PZT modulation frequencies. The dominant contribution to the noise is actually likely to result from the beat between various frequencies with similar values, namely from the laser jitter, the PZT modulation and the FTIR sampling process. The resulting beat is smoothed out due to the detector response time $(\sim 1 \mu \mathrm{s})$, actually lengthened by the use of a lowpass frequency filter. This effect is more efficient if the PZT 
modulation is higher. The remaining noise at $20 \mathrm{kHz}$ PZT modulation, which is channeling, can actually be removed from real spectra by producing a transmittance signal, i.e. dividing by $\mathrm{I}_{0}$. It is likely that even higher modulation will help in this problem. All other spectra presented here were recorded using $20 \mathrm{kHz}$ modulation frequency.

The effect of the FTIR resolution is illustrated in Figure 6 with spectra recorded with $0.04,0.02,0.01$ and $0.005 \mathrm{~cm}^{-1}$ resolution, from bottom to top. It is worth noting that a discretization of the spectrum starts appearing at $0.02 \mathrm{~cm}^{-1}$ FTIR resolution and is well present at $0.005 \mathrm{~cm}^{-1}$ FTIR resolution, giving rise to spike-like background signal. It is due to the free spectral range (FSR) of the fixed laser comb $(F S R=80 \mathrm{MHz})$, limiting the final resolution.

We also checked that $\mathrm{S} / \mathrm{N}$ increases as the square root of the number of scans $(n)$ as expected for white noise.

\section{Data and conclusion}

We used optimal conditions to record the $v_{1}+v_{3}$ band in $\mathrm{C}_{2} \mathrm{H}_{2}$, as shown on Figure 7. It corresponds to an optimal rms noise equivalent absorption of $2.210^{-9} \mathrm{~cm}^{-1} \mathrm{~Hz}^{-1 / 2}$ per spectral element, and a value $\bullet_{\min }$ of $1.510^{-7} \mathrm{~cm}^{-1}$. 
These values are about 60 times better than those for the off-axis CEAS experiment previously reported (Figure 3). This improvement results from the increase in pathlength (30 times improvement) and also (another factor of 2) from the new design, involving an optical isolator and the fine tuning of the cavity, therefore decreasing the noise. This band and the many accompanying bands in the range have already been investigated in the literature using conventional FTIR multipass set-ups (e.g. (31-33)). Recently, ultra high sensitivity cavity ring down spectroscopy (CRDS) was applied in the range $(30,34)$, revealing many more, weaker bands. The data recorded using Femto-FT-CEAS are of intermediate quality. We could spot lines not reported in the conventional FTIR investigations. Some of these were actually not assigned in the CRDS data, yet. Taking advantage on the very precise global modeling of the acetylene vibration-rotation energy levels in acetylene available from the literature and of the accurate resulting spectral simulations (30), we assigned low J-lines transitions in two bands, as reported in Table 1 . All lines in these bands correspond to weak transitions, some overlapped by stronger lines and therefore missing in the Table. Some of the lines are highlighted in Figure 8.

In conclusion, the experiments just reported demonstrate that FemtoFT-CEAS can be successfully achieved using a tunable broadband OPO source. Various limitations existing with our present set-up were highlighted, 
as well as directions for improvement. These include access to higher PZT modulation frequency and improvement of the mirrors quality (a reflectivity of $99.9 \%$, in a larger bandwidth should be easily compatible with the actual set-up).

Compared to CW-CRDS, sensitivity and resolution are not as high with Femto-FT-CEAS but recording speed and spectral bandwidth are significantly improved. Also, internal calibration procedure and data processing is ensured by the FTIR software and readily available. The many different possible recording conditions make a more quantitative comparison between CRDS and Femto-FT-CEAS difficult. It is clear, for instance that when combined to jet cooled experiments as used in our lab $(28,29)$, both would address different types of problems, the former to be focused on exploring the absorption spectrum over a broad range, the latter to be dedicated to high sensitivity and high resolution investigations.

Two of the major advantages of Femto-FT-CEAS using a broadband OPO absorption source compared to more conventional FTIR approaches are that (i) thanks to the source brightness, high quality data can be recorded in a short amount of time, and (ii) the cell volume is much smaller (less than $200 \mathrm{cc}$ in the present case) than for conventional multipass designs for identical or even larger pathlengths. We actually hope to benefit from the first of these by implementing Femto-FT-CEAS around the supersonic 
expansion of FANTASIO+ in the very near future. We hope to exploit the second advantage by recording NIR spectra of rare isotopologues, usually to expensive to fill in a large multipass cell. Of particular relevance are all those isotopologues of acetylene investigated in the MIR by Di Lonardo and coauthors, including ${ }^{12} \mathrm{C}_{2} \mathrm{HD}$ (35-39), ${ }^{12} \mathrm{CH}^{13} \mathrm{CH} \quad(40-50),{ }^{13} \mathrm{C}_{2} \mathrm{H}_{2} \quad(40,41,51-55)$, ${ }^{12} \mathrm{C}_{2} \mathrm{D}_{2}$ (56-58), ${ }^{13} \mathrm{C}_{2} \mathrm{D}_{2}$ (59-62), ${ }^{13} \mathrm{C}_{2} \mathrm{HD}$ (63), $\mathrm{H}^{12} \mathrm{C}^{13} \mathrm{CD}$ and $\mathrm{H}^{13} \mathrm{C}^{12} \mathrm{CD}$ (64) (not forgetting $\left.{ }^{12} \mathrm{C}_{2} \mathrm{H}_{2} \quad(52,53,55,65,66)\right)$ for which the information could be extended towards the NIR, with the help of the Bologna group.

\section{Acknowledgments}

We are happy to dedicate this paper to Prof. Di Lonardo, for his many contributions to the acetylene spectroscopy, a dedication shared with all of us. We thank B. Amyay and P. Van Poucke (ULB) for their help on various items. We are indebted to the "programme Currien/Tournesol" collaboration sponsored by "Wallonie Bruxelles international ", F.R.S.-FNRS and "Région Wallone", and 'Ministère des Affaires étrangères" and "Ministère de l'Education Nationale, de la Recherche et de la Technologie" on the Belgian and French sides, respectively. This work was also sponsored in Belgium, by the Fonds National de la Recherche Scientifique (FNRS, contracts FRFC and IISN) and the "Action de Recherches Concertées de la Communauté française de Belgique». 


\section{References}

(1) ST Ridgway, JW Brault: Annu. Rev. Astron. Astrophys. 22 (1984) 291317.

(2) JW Brault: Philos. Trans. R. Soc. London, Ser. A 307 (1982) 503-11.

(3) HA Gobbie, G Roland, L Delbouille: Nature (London, U. K.) 191 (1961) 264-5.

(4) L Delbouille, M Migeotte: J. Opt. Soc. Am. 50 (1960) 1305-7.

(5) G Guelachvili: Opt. Commun. 8 (1973) 171-5.

(6) M Betrencourt, M Morillon-Chapey, C Amiot, G Guelachvili: J. Mol. Spectrosc. 57 (1975) 402-15.

(7) DJW Kendall, HL Buijs, JWC Johns: J. Mol. Struct. 79 (1982) 39-42.

(8) M Herman, JWC Johns, ARW McKellar: J. Mol. Spectrosc. 95 (1982) 405-12.

(9) J Kauppinen: Appl Opt 14 (1975) 1987-92.

(10) J Kauppinen, M Taanila: Commentat. Phys.-Math., Soc. Sci. Fenn. 42 (1972) 318-19.

(11) J Chazelas, J Pliva, A Valentin, L Henry: J. Mol. Spectrosc. 110 (1985) 326-38.

(12) G Pierre, A Valentin, L Henry: Can. J. Phys. 62 (1984) 254-9.

(13) BP Winnewisser, M Winnewisser: Proc. SPIE-Int. Soc. Opt. Eng. 1145 (1989) 28-33. 
(14) J Vogt, M Winnewisser, K Yamada, G Winnewisser: Chem. Phys. 83 (1984) 309-18.

(15) ARW McKellar: J. Mol. Spectrosc. 262 (2010) 1-10.

(16) J Mandon, G Guelachvili, N Picque, F Druon, P Georges: Opt. Letters 32 (2007) 1677-79.

(17) J Mandon, G Guelachvili, N Picque: Nature Photonics (2009) 99-102.

(18) J Orphal, AA Ruth: Opt. Express 16 (2008) 19232-43.

(19) R Engeln, G Meijer: Rev. Sci. Instrum. 67 (1996) 2708-13.

(20) R Engeln, E Van den Berg, G Meijer, L Lin, GMH Knippels, AFG Van der Meer: Chem. Phys. Letters 269 (1997) 293-97.

(21) S Kassi, C Depiesse, M Herman, D Hurtmans: Mol. Phys. 101 (2003) 1155-63.

(22) SM Hu, A Campargue, ZY Wu, Y Ding, AW Liu, QS Zhu: Chem. Phys. Letters 372 (2003) 659-67.

(23) S Kassi, K Didriche, C Lauzin, X de Ghellinck d'Elseghem Vaernewijck, A Rizopoulos, M Herman: Spectrochim. Acta, A 75A (2010) 142-45.

(24) B Bernhardt, A Ozawa, P Jacquet, M Jacquey, Y Kobayashi, T Udem, R Holzwarth, G Guelachvili, TW Haensch, N Picque: Nat. Photonics 4 (2009) 55-57.

(25) T Gherman, S Kassi, A Campargue, D Romanini: Chem. Phys. Letters 383 (2004) 353-58. 
(26) T Gherman, D Romanini: Optics Express 10 (2002) 1033-42.

(27) M Herman, K Didriche, D Hurtmans, B Kizil, P Macko, A Rizopoulos, P Van Poucke: Mol. Phys. 105 (2007) 815-23.

(28) K Didriche, C Lauzin, T Foldes, X. de Ghellinck d'Elseghem Vaernewijck, M Herman: Mol. Phys. 108 (2010) 2155-63.

(29) K Didriche, C Lauzin, T Foldes, D Golebiowski, M Herman, C Leforestier: PCCP doi: 10.1039/c1cp2059561g (2011).

(30) B Amyay, M Herman, A Fayt, A Campargue, S Kassi: J. Mol. Spectrosc. doi:10.1016/j.jms.2011.02.015 (2011).

(31) BC Smith, JS Winn: J. Chem. Phys. 89 (1988) 4638-45.

(32) Q Kou, G Guelachvili, M Abbouti Temsamani, M Herman: Can. J. Phys. 72 (1994) 1241-50.

(33) KA Keppler, GC Mellau, S Klee, BP Winnewisser, M Winnewisser, J Plíva, KN Rao: J. Mol. Spectrosc. 175 (1996) 411-20.

(34) S Robert, M Herman, A Fayt, A Campargue, S Kassi, A Liu, L Wang, G Di Lonardo, L Fusina: Mol. Phys. 106 (2008) 2581-605.

(35) M Herman, C Depiesse, G Di Lonardo, A Fayt, L Fusina, D Hurtmans, S Kassi, M Mollabashi, J Vander Auwera: J. Mol. Spectrosc. 228 (2004) 499-510.

(36) L Fusina, E Cane, F Tamassia, G Di Lonardo: Mol. Phys. 103 (2005) 3263-70.

(37) L Fusina, F Tamassia, G Di Lonardo: Mol. Phys. 103 (2005) 2613-20. 
(38) A Jolly, Y Benilan, E Cané, L Fusina, F Tamassia, A Fayt, S Robert, M Herman: J. Quant. Spectrosc. Radiat. Transfer 109 (2008) 2846-56.

(39) A Predoi-Cross, M Herman, L Fusina, G Di Lonardo: Mol. Phys. 109 (2011) 559-63.

(40) G Di Lonardo, P Ferracuti, L Fusina, E Venuti, JWC Johns: J. Mol. Spectrosc. 161 (1993) 466-86.

(41) G Di Lonardo, P Ferracuti, L Fusina, E Venuti: J. Mol. Spectrosc. 164 (1994) 219-32.

(42) F Alboni, G Di Lonardo, P Ferracuti, L Fusina, E Venuti, KA Mohamed: J. Mol. Spectrosc. 169 (1995) 148-53.

(43) G Di Lonardo, A Baldan, G Bramati, L Fusina: J. Mol. Spectrosc. 213 (2002) 57-63.

(44) L Fusina, G Bramati, A Mazzavillani, G Di Lonardo: Mol. Phys. 101 (2002) 513-21.

(45) C Depiesse, G Di Lonardo, A Fayt, L Fusina, D Hurtmans, S Robert, F Tamassia, J Vander Auwera, A Baldan, M Herman: J. Mol. Spectrosc. 229 (2005) 137-39.

(46) S Robert, A Fayt, G Di Lonardo, L Fusina, F Tamassia, M Herman: J Chem Phys 123 (2005) 174302.

(47) G Di Lonardo, L Fusina, F Tamassia, A Fayt, S Robert, J Vander Auwera, M Herman: Mol. Phys. 104 (2006) 2617-25. 
(48) A Fayt, S Robert, G Di Lonardo, L Fusina, F Tamassia, M Herman: J. Chem. Phys. 126 (2007) 114303.

(49) G Di Lonardo, L Fusina, F Tamassia, A Fayt, S Robert, J Vander Auwera, M Herman: Mol. Phys. 106 (2008) 1161-69.

(50) S Robert, B Amyay, A Fayt, G Di Lonardo, L Fusina, F Tamassia, M Herman: J Phys Chem A 113 (2009) 13251-9.

(51) E Venuti, G Di Lonardo, P Ferracuti, L Fusina, IM Mills: Chem. Phys. 190 (1995) 279-90.

(52) M Becucci, E Castellucci, L Fusina, G Di Lonardo, HW Schrotter: J. Raman Spectrosc. 29 (1998) 237-41.

(53) D Bermejo, P Cancio, G Di Lonardo, L Fusina: J. Chem. Phys. 108 (1998) 7224-28.

(54) G Di Lonardo, L Fusina, E Venuti, JWC Johns, MI El Idrissi, J Liévin, M Herman: J. Chem. Phys. 111 (1999) 1008-16.

(55) D Bermejo, RZ Martinez, G Di Lonardo, L Fusina: J. Chem. Phys. 111 (1999) 519-24.

(56) M Herman, IMI El, A Pisarchik, A Campargue, AC Gaillot, L Biennier, G Di Lonardo, L Fusina: J. Chem. Phys. 108 (1998) 1377-89.

(57) D Bermejo, G Di Lonardo, JL Doménech, L Fusina: J. Mol. Spectrosc. 209 (2001) 259-66.

(58) S Robert, M Herman, J Vander Auwera, G Di Lonardo, L Fusina, G Blanquet, M Lepere, A Fayt: Mol. Phys. 105 (2007) 559-68. 
(59) E Cane, G Cazzoli, G Di Lonardo, L Dore, R Escribano, L Fusina: J. Mol. Spectrosc. 216 (2002) 447-53.

(60) D Bermejo, G Di Lonardo, JL Doménech, L Fusina: Mol. Phys. 100 (2002) 3493-97.

(61) D Bermejo, G Di Lonardo, JL Domenech, L Fusina: Mol. Phys. 101 (2003) 3203-12.

(62) D Bermejo, G Di Lonardo, JL Domenech, L Fusina: J. Mol. Spectrosc. 219 (2003) 290-95.

(63) L Fusina, F Tamassia, G Di Lonardo, A Baldan: Mol. Phys. 107 (2009) 2119-26.

(64) L Fusina, E Cané, F Tamassia, G Di Lonardo: Mol. Phys. 105 (2007) $2321-25$

(65) Y Kabbadj, M Herman, G Di Lonardo, L Fusina, JWC Johns: J. Mol. Spectrosc. 150 (1991) 535-65.

(66) S Robert, M Herman, A Fayt, A Campargue, S Kassi, A Liu, L Wang, G Di Lonardo, L Fusina: Mol. Phys. 106 (2008) 2581-605. 


\section{Figure captions}

Figure 1: Illustration of the broad spectral coverage using a femto OPO absorption source and FTIR, in the NIR portion of the OPO emission. Absorption lines are from atmospheric water. OPO emission has $90 \mathrm{~cm}^{-1}$ FWHM spectral coverage in the lower energy range.

Figure 2: FTIR absorption spectrum of $v_{1}+v_{3}, \mathrm{C}_{2} \mathrm{H}_{2}$ recorded using FANTASIO+, a multipass optics set to 25 passes and a femto OPO absorption source. Input and output pressures around the $0.5 \mathrm{~mm}$ circular nozzle: 1355 Torr and 14 mTorr, respectively; Flow rates: 2,2 l/min $\left(\mathrm{C}_{2} \mathrm{H}_{2}\right)$ and 1,8 l/min (Ar, carrier gas); FTIR resolution: $310^{-2} \mathrm{~cm}^{-1}$.

Figure 3: FTIR absorption spectrum of $v_{1}+v_{3}, \mathrm{C}_{2} \mathrm{H}_{2}$ recorded using off-axis CEAS design and a femto OPO absorption source (top), compared to simulation (bottom) (saturated peaks were removed from the data points). Experimental conditions: P: 2 Torr; FTIR resolution: 0.005 $\mathrm{cm}^{-1}$; Absorption pathlength: $5 \mathrm{~m}$.

Figure 4: Experimental design for Femto-FT-CEAS using an OPO tunable source. Laser: Chameleon Ultra II, P810 OPO Signal or Idler; OI: optical isolator; M1, L1, L2, M3, M4, L3: steering optics; CM1, CM2: 
high reflective cavity mirrors (99.5\%); FTIR: Bruker IFS 120 HR; PZT: Piezoelectric modulator.

Figure 5: FTIR absorption spectrum (arbitrary intensity units) of a femto OPO source injected in a high finesse cavity for various PZT modulation frequencies: $0,20,200,2000,20000 \mathrm{~Hz}$ from top to bottom. Experimental conditions: Resolution: $0.02 \mathrm{~cm}^{-1} ; 10$ accumulated scans.

Figure 6: Portion of the Femto-FT-CEAS spectrum of $v_{1}+v_{3}, \mathrm{C}_{2} \mathrm{H}_{2}$ recorded using an OPO absorption source, for various FTIR resolutions: 0.04, $0.02,0.01,0.005 \mathrm{~cm}^{-1}$ from bottom to top.

Experimental conditions: P: 2 Torr; Absorption pathlength: $150 \mathrm{~m} ; 10$ accumulated scans.

Figure 7: FTIR spectrum of $v_{1}+v_{3}, \mathrm{C}_{2} \mathrm{H}_{2}$ recorded using CEAS design and a femto OPO absorption source (saturated peaks were removed from the data points). Experimental conditions: P: 10 Torr; FTIR resolution: $0.02 \mathrm{~cm}^{-1} ; 180$ accumulated scans.

Figure 8: Portions of the spectrum of $v_{1}+v_{3}, \mathrm{C}_{2} \mathrm{H}_{2}$ shown on Figure 8. Newly assigned $\mathrm{R}$ and $\mathrm{P}$ transitions are indicated by arrows. Top/bottom figures highlight (a)/(b) bands identified in Table 1, respectively. 


\section{Table 1}

\begin{tabular}{|l|l|r|r|}
\hline \multicolumn{1}{|l|}{ Calc. } & Ass. & \multicolumn{1}{|c|}{ Obs. } & Obs.-Calc. \\
\hline (a)1 1 0 2 2, 2 0eg- 00011,1 & 1 eu \\
\hline 6557.324 & P5 & 6557.330 & 0.006 \\
\hline 6583.118 & R5 & 6583.104 & -0.014 \\
\hline 6589.857 & R8 & 6589.849 & -0.008 \\
\hline 6596.499 & R11 & 6596.493 & -0.006 \\
\hline 6598.695 & R12 & 6598.685 & -0.010 \\
\hline (b) 1 1 2 2, 2 -2eg- $00011,1-1$ \\
\hline 6547.532 & P10 & 6547.538 & 0.006 \\
\hline 6552.536 & P8 & 6552.530 & -0.006 \\
\hline 6557.466 & P6 & 6557.460 & -0.006 \\
\hline 6559.906 & P5 & 6559.903 & -0.003 \\
\hline 6562.329 & P4 & 6562.327 & -0.001 \\
\hline 6578.854 & R2 & 6578.850 & -0.004 \\
\hline 6581.152 & R3 & 6581.153 & 0.001 \\
\hline 6587.939 & R6 & 6587.923 & -0.016 \\
\hline 6590.163 & R7 & 6590.163 & 0.000 \\
\hline 6592.366 & R8 & 6592.360 & -0.006 \\
\hline 6596.705 & R10 & 6596.691 & -0.014 \\
\hline
\end{tabular}

\section{Table caption}

\section{Table 1}

Transitions assigned in ${ }^{12} \mathrm{C}_{2} \mathrm{H}_{2}$. The bands are identified using conventional numbering (30): $v_{1} v_{2} v_{3} v_{4} v_{5}, l_{4} l_{5} e / f, u / g$. The predicted line wavenumbers (from (30)), rotational assignments, observed and observed-predicted wavenumbers (all positions in $\mathrm{cm}^{-1}$ ) are provided. 


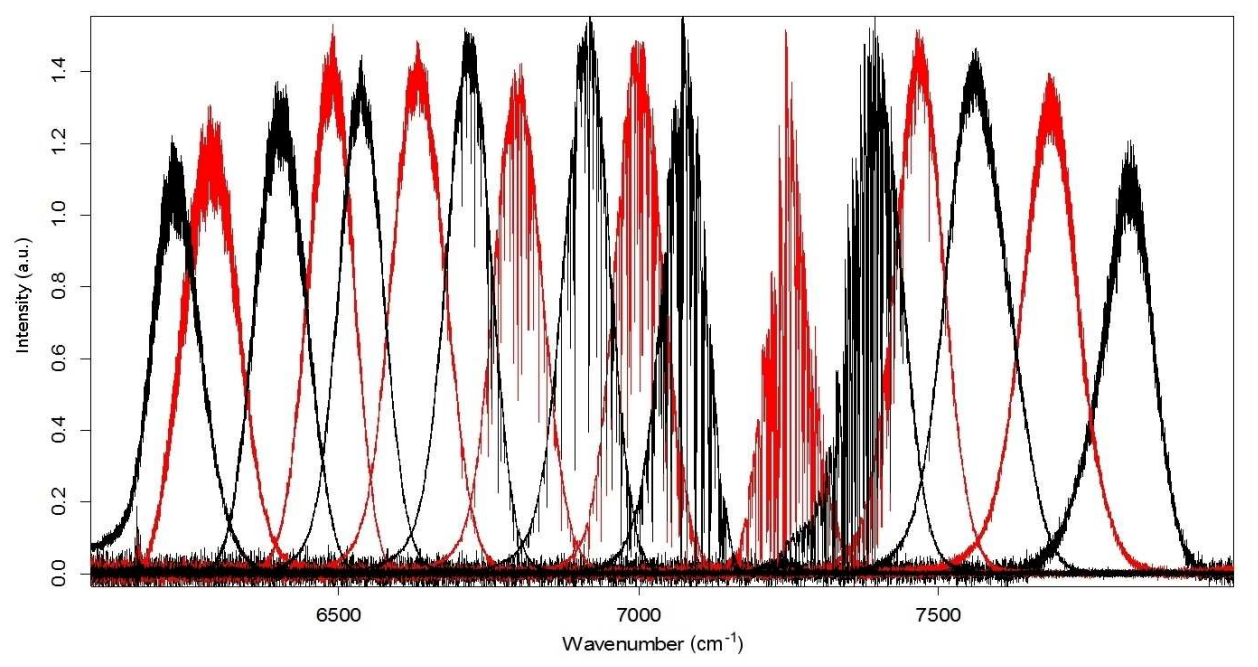

$508 \times 264 \mathrm{~mm}(72 \times 72$ DPI $)$ 
1

2

3

4

5

6

7

8

9

10

11

12

13

14

15

16

17

18

19

20

21

22

23

24

25

26

27

28

29

30

31

32

33

34

35

36

37

38

39

40

41

42

43

44

45

46

47

48

49

50

51

52

53

54

55

56

57

58

59

60

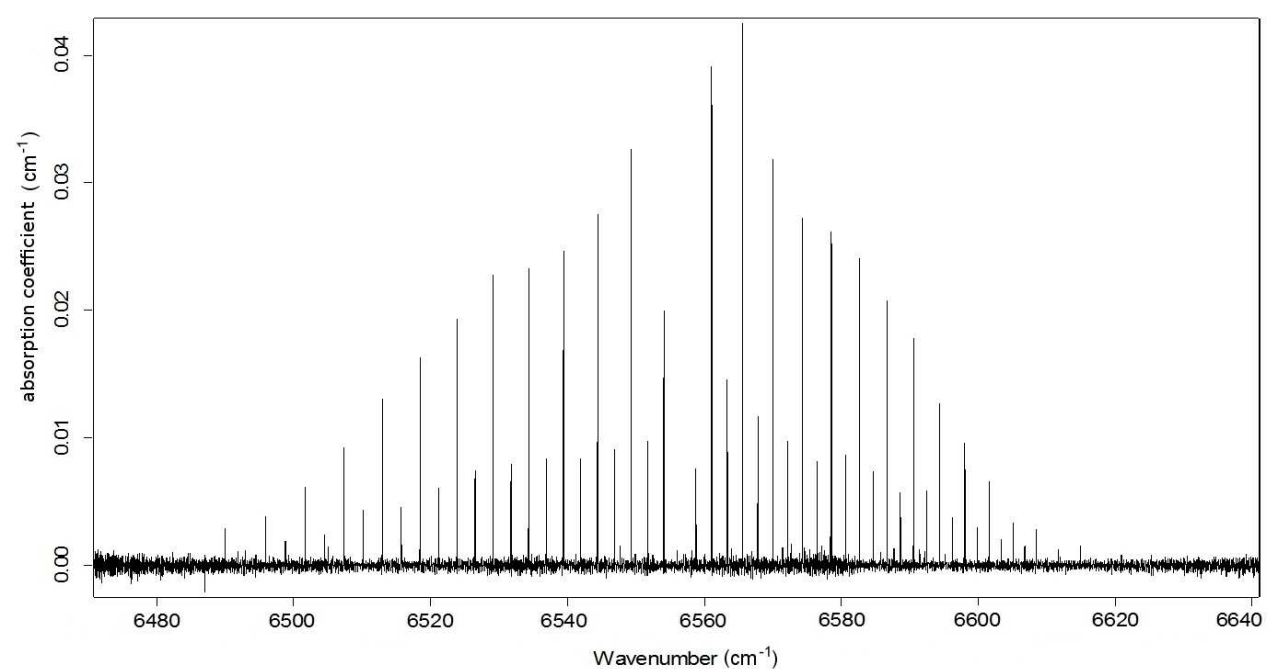

$498 \times 258 \mathrm{~mm}(72 \times 72$ DPI $)$

URL: http://mc.manuscriptcentral.com/tandf/tmph 


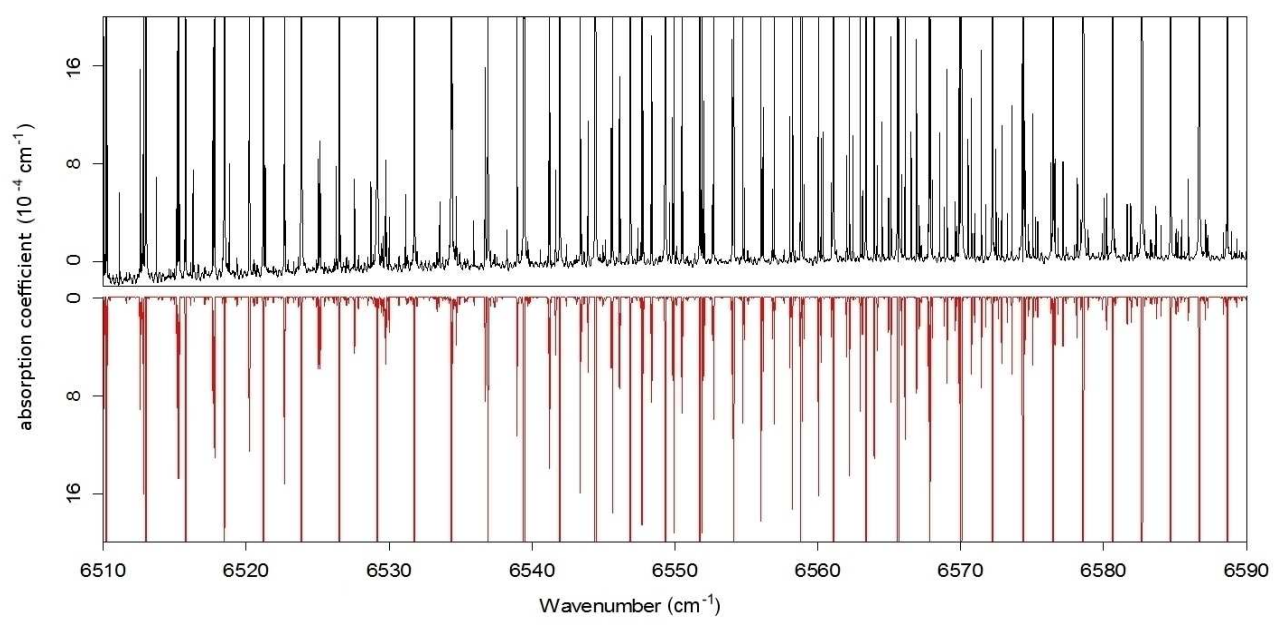

$508 \times 246 \mathrm{~mm}(72 \times 72$ DPI $)$

1
2
3
4
5
6
7
8
9
10
11
12
13
14
15
16
17
18
19
20
21
22
23
24
25
26
27
28
29
30
31
32
33
34
35
36
37
38
39
40
41
42
43
44
45
46
47
48
49
50
51
52
53
54
55
56
57
58
59
60




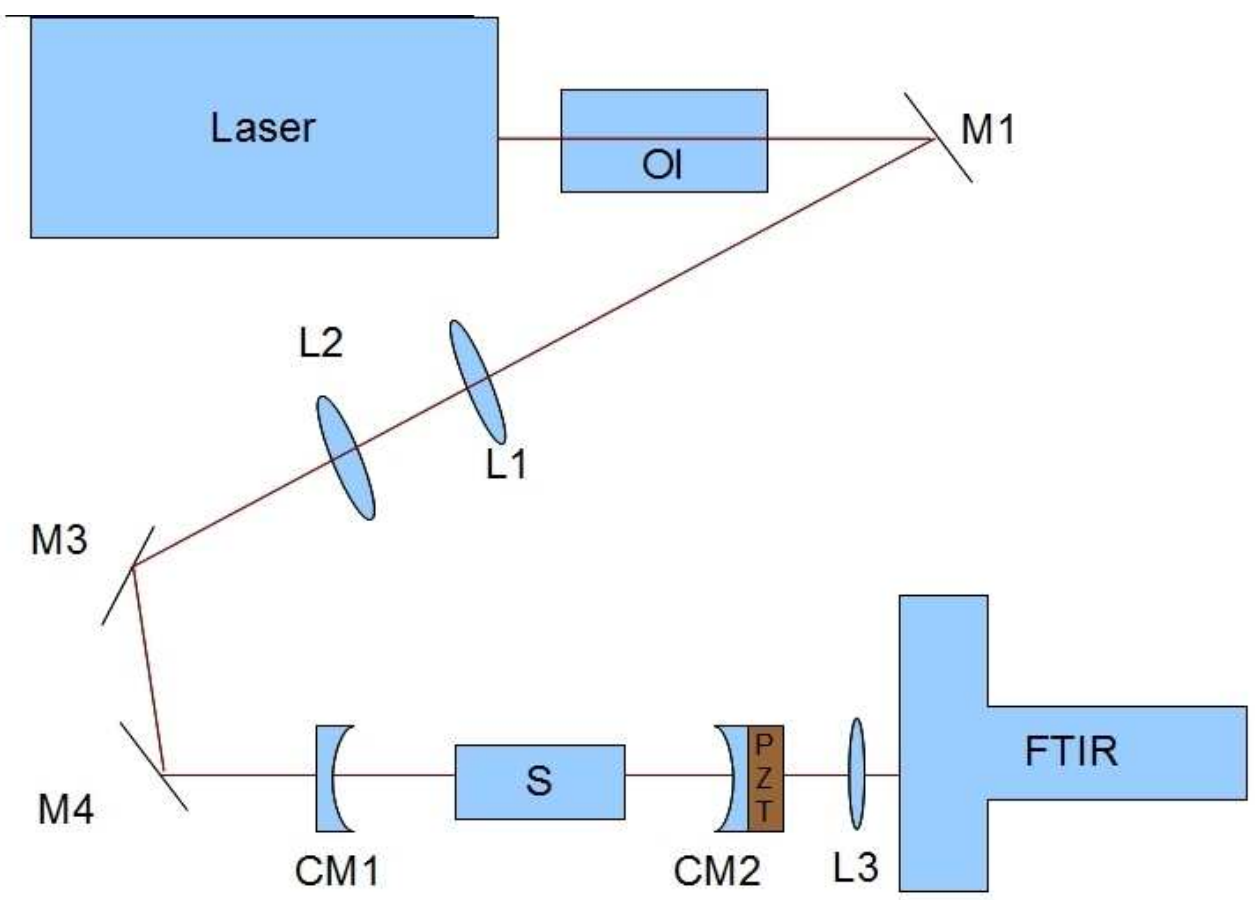

$261 \times 186 \mathrm{~mm}(72 \times 72 \mathrm{DPI})$

URL: http://mc.manuscriptcentral.com/tandf/tmph 


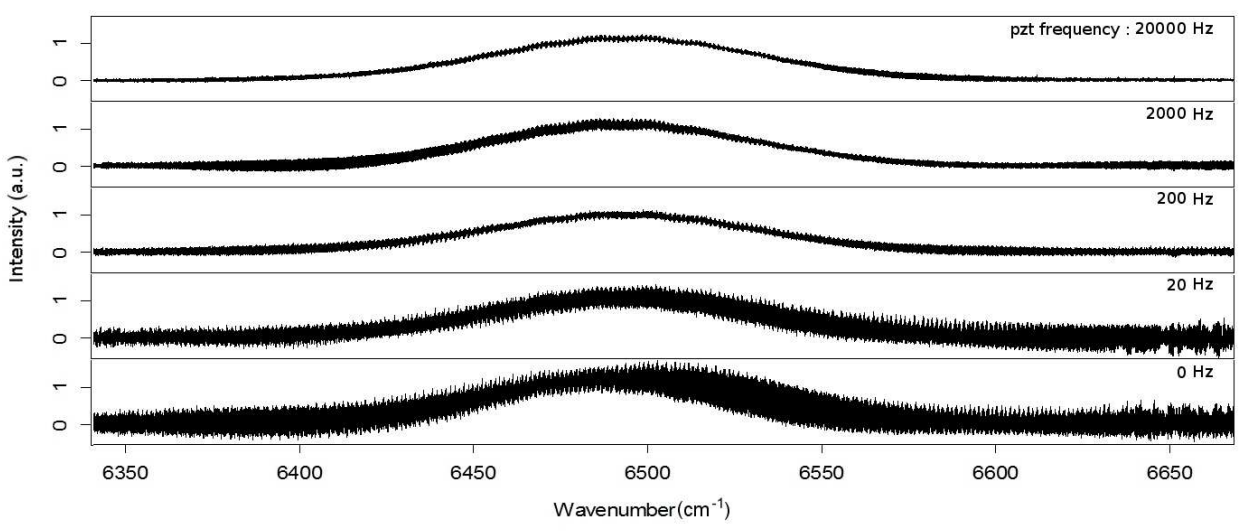

$508 \times 211 \mathrm{~mm}(72 \times 72 \mathrm{DPI})$

1

2

3

4

5

6

7

9

10

11

12

13

14

16

17

18

19

20

21

22

23

24

25

26

27

28

29

30

31

32

33

34

35

36

37

38

39

40

41

42

43

44

45

46

47

48

49

50

51

52

53

54

55

56

57

58

59

60

URL: http://mc.manuscriptcentral.com/tandf/tmph 


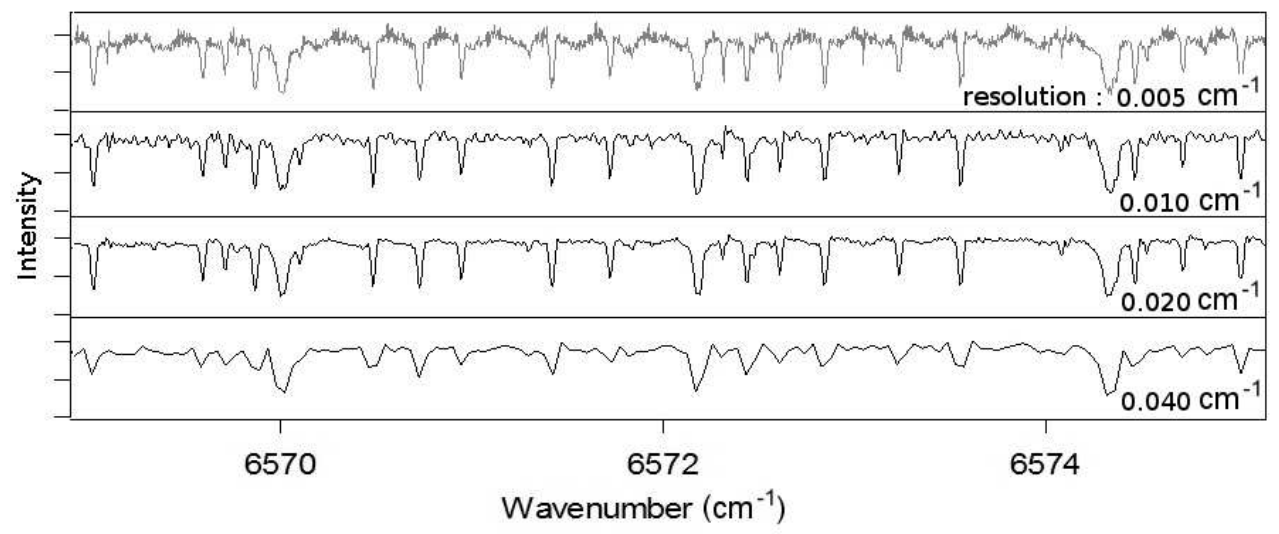

$324 \times 139 \mathrm{~mm}(72 \times 72 \mathrm{DPI})$ 


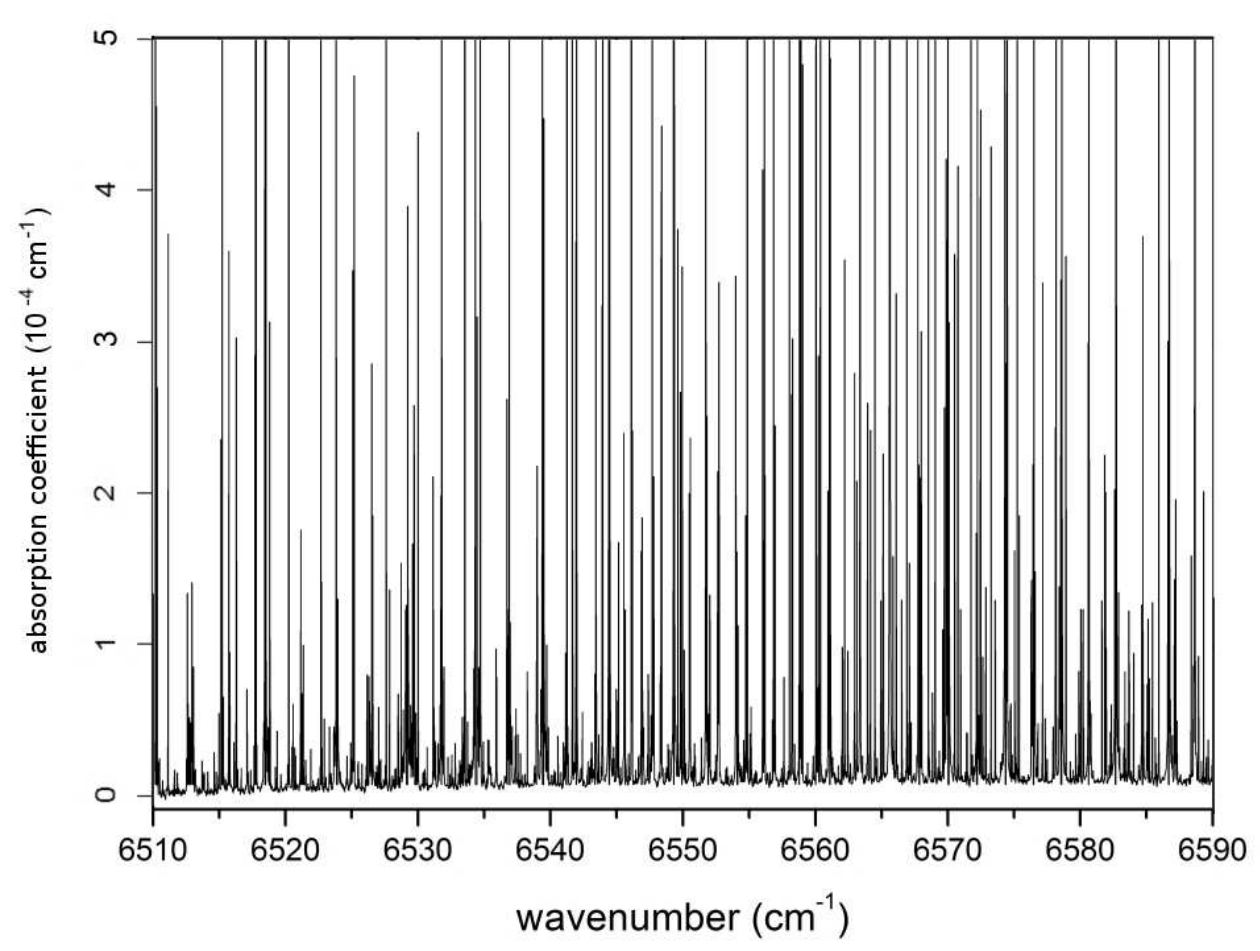

$83 \times 63 \mathrm{~mm}(300 \times 300$ DPI $)$ 

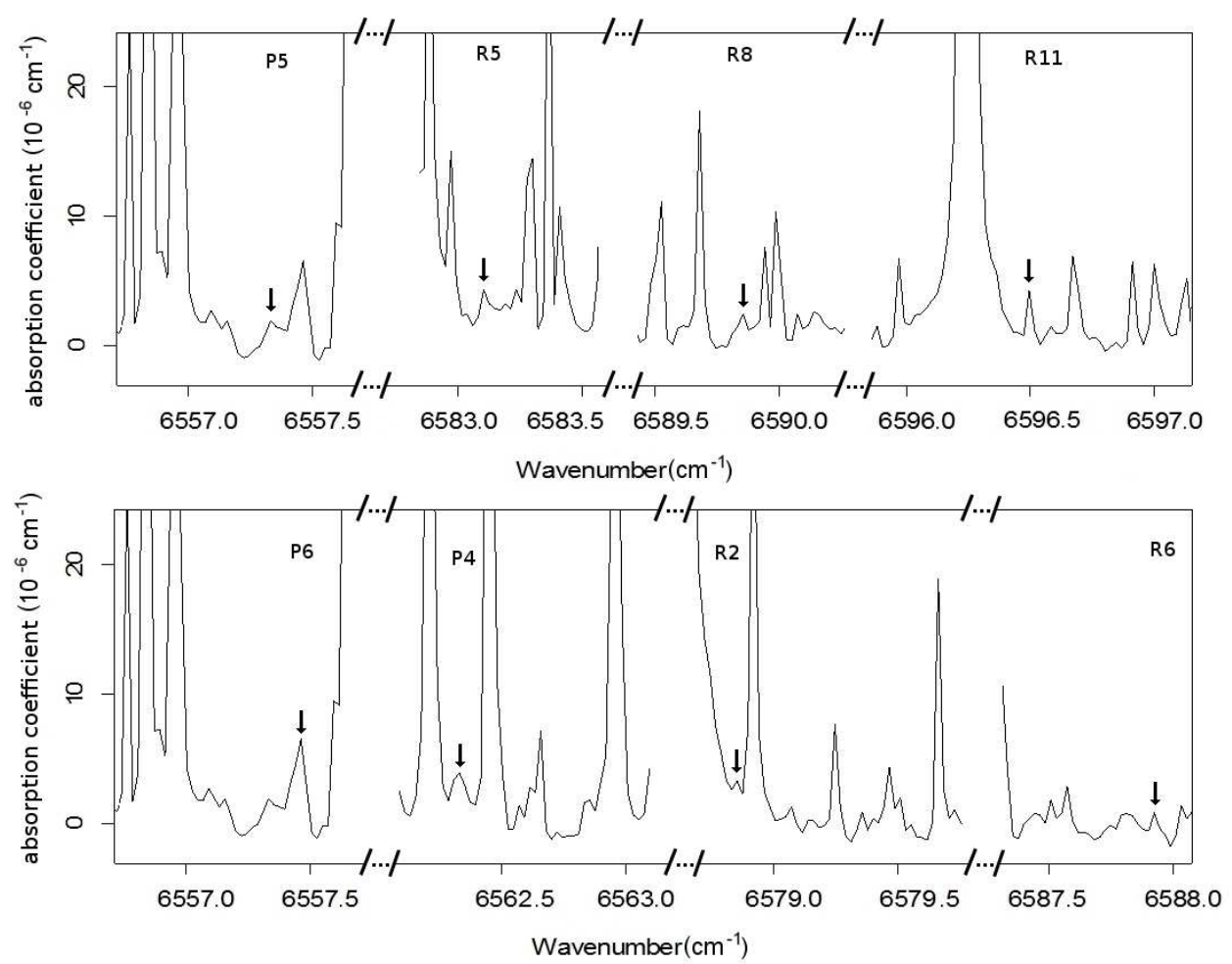

$402 \times 317 \mathrm{~mm}(72 \times 72$ DPI $)$ 